\section{OUTCOMES FOR FACILITATORS THROUGH WORKPLACE ENVIRONMENTAL IMPROVEMENT USING A PARTICIPATORY APPROACH}

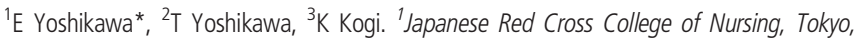
Japan; ${ }^{2}$ National Institute of Occupational Safety and Health, Kawasaki, Japan; ${ }^{3}$ The Ohara Memorial Institute for Science of Labour, Tokyo, Japan

\subsection{6/oemed-2018-ICOHabstracts. 1402}

Introduction The purpose of this study was to determine changes in awareness, behaviour, and relationships of facilitators who were involved in participatory workplace environment improvement and to examine the outcome components that led to meaningful workplace organisation resulting in workplace environmental improvements through a participatory approach. It is useful to clarify these outcome components in relationship to associations among various factors.

Methods An anonymous self-administered questionnaire survey was conducted for 91 facilitators in three organisations. Valid responses from 79 facilitators (91.9\%) were analysed. Changes in awareness, behaviour and relationships as a result of participatory workplace environment improvement were studied. A conceptual framework of the outcome of changes in the overall workplace organisation was set as a tentative model. Exploratory factor analysis was used to determine outcome elements for the facilitators in the participatory process by means of hierarchal regression analysis. This study was approved by the ethics review committee of St. Luke's International University (13-042).

Results Outcomes for facilitators consisted of four sub-concepts corresponding to 'developing self-confidence,' 'improving work-related risk sensitivity,' 'gaining better-than-expected results based on establishing relationships with workers' and 'knowing practical ways and strategies to ensure full participation.' The range of Cronbach's alpha of the subscales was $0.82-0.95$. The results of hierarchal regression analysis indicated that sub-concepts of 'knowing practical ways and strategies to ensure full participation' were significantly associated with age $(B=-0.261, p=0.042)$, and that 'developing self-confidence' was significantly associated with active participation $(B=0.348, p=0.006)$ and number of improvements $(B=0.251$, $\mathrm{p}=0.042)$.

Conclusion The outcomes revealed confirmed the importance of applying practical ways to secure active participation of workers/managers at the workplace level. These outcomes were associated with satisfaction of improvements based on experiences of these improvements. Supporting satisfaction of improvements in the follow-up activities was considered useful for effective workplace environment improvement.

\section{ISSUES \& CHALLENGES FOR OPERATIONALIZING BOHS IN AN UN-ORGANISED LABOUR MARKET, MUMBAI, INDIA}

Ganesh K Kulkarni ${ }^{*}$, R Rajesh, Nikunj Desai, Nandkumar Valanju. Indian Association of Occupational Health, Mumbai, India

\subsection{6/oemed-2018-ICOHabstracts. 1403}

Introduction The total work force in India is 537.4 Million and 496.4 million $(92.38 \%)$ work in informal or un-organised sector of economy. There are 22 main listed occupations like agriculture, Building and Construction, Animal Husbandry, Beedi making etc. but there are many unlisted occupations in
India where access to Basic occupational health Service is nonexistent. A project initiated by Indian association of Occupational Health to provide BOHS in a labour market in Mumbai in March-April 2017 through an NGO partner. Issues and Challenges in operationalizing BOHS are shared in this presentation.

Methods An NGO partner was identified as operating agency and IAOH as a Technical and resource partner, a walkthrough survey was undertaken in a Mumbai un-organised Labour market and observations recorded. A meeting was held with representatives from cross section of un-organised labours to assess the needs of the labour market and create a BOHS action plan with partner NGO.

Results The labour group expressed need for a) First-aid kit and training, b) preventive Tetanus vaccination c) Pragmatic safety solutions. The concept of Minimal Occupational Health Services was thus arrived at that can be upgraded to BOHS later.

Conclusion A project 'Hamara Gala, Suraksha Gala' was envisaged and first-aid training was organised on 2 April 2017. The employer sensitisation was done by NGO partner, IAOH provided financial resources, faculty, training material and first-aid kits to 33 participating labour from different Industrial shops (Galas) that included 4 labour employers. Attendance certificate were issued to all the participants. The major issues were access to BOHS, Employer concerns, Socio-political challenges and disability management. To sustain the program, the NGO partner shall do quarterly inspections and report to $\mathrm{IAOH}$. The vaccination and pragmatic safety are being planned in a phased manner.

\section{A MULTI-DISCIPLINARY INTER-CONTINENTAL COLLABORATION TO BUILD CAPABILITY IN OCCUPATIONAL HEALTH AMONG HEALTH CARE PROFESSIONALS}

Inakshi Naik, Ashish Mittal, Robin Nicholas, Mahinda Seneviratne. Retired, Johannesburg, Guateng, South Africa

\subsection{6/oemed-2018-ICOHabstracts. 1404}

The interaction between community, environment and the workplace is crucial in the provision of basic health care services in low resource/low income countries. UN's Sustainable development Goals and strategies of agencies WHO and ILO and professional bodies such as ICOH and IALI have highlighted the need for capability building and integration in delivering the necessary services to these communities. However, health care professionals, including medical doctors and nurses undergo limited training in occupational health during their professional undergraduate education.

A series of workshops for health care professionals to develop knowledge and basic skills in workplace hazard identification, assessment and control were conducted in India and Malaysia. The multi-disciplinary program involving occupational medicine, hygiene, ergonomics and hazard communication was delivered by a group of occupational health professionals from four different continents. Their time and resources were provided voluntarily and at no fee or charge for the local organisers.

The workshops consisted primarily of interactive group work facilitated by skilled specialists sharing their international experiences together with demonstration of case studies by 